\title{
Patê de peixe usando resíduos da indústria pesqueira amazônica: produção e aceitação
}

O aumento da demanda de pescado beneficiado para exportação acarreta aumento nos subprodutos (cabeças, vísceras e espinhas entre outros), potencialmente valiosos, caso sejam transformados em novos produtos. Essa pesquisa buscou apontar os aspectos produtivos e a aceitabilidade do patê de peixe preparado a partir de resíduos de dourada (Brachyplatystoma rousseauxii) suplementado com o pirarucu (Arapaima gigas) defumado, utilizando os espessantes naturais batata e macaxeira. A partir das carcaças de dourada, foi efetuada a extração da massa muscular, que posteriormente foi triturada e lavada; os pedaços de lombo de pirarucu foram defumados e reservados. Todos os ingredientes foram homogeneizados em multiprocessador. Foram quantificadas: a) contaminação microbiológica da massa; b) os rendimentos de massa muscular e triturado lavados de dourada, mais o pirarucu defumado; c) a aceitabilidade das diferentes formulações do patê de dourada incrementada com pirarucu defumado. As formulações foram F43M, F43B, F39M e F39B, onde o número indica a quantidade de peixe e a última letra, o espessante utilizado. A massa apresentou baixo índice de contaminação microbiana. Os rendimentos foram satisfatórios, e permitem apontar que a transformação dessa massa em patê reduz em 16,98\% o descarte de resíduos na natureza. A maior aceitabilidade do patê foi na formulação com menor quantidade de dourada associada com a batata como espessante. Apesar de serem necessárias mudanças nas formulações sugeridas, constatou-se a viabilidade do uso de resíduos da indústria pesqueira para produção de patê destinado ao consumo humano, potencialmente reduzindo $170 \mathrm{~kg}$ de material descartado na natureza a cada 1 ton de resíduos do beneficiamento industrial.

Palavras-chave: Carcaça; Pescado; Pasta; Indústria; Consumo.

\section{Fish pate using waste from the Amazon fishing industry: production and acceptance}

\begin{abstract}
Increasing demand for export-benefited fish leads to potentially valuable by-products (heads, offal and pimples, among others) if they are turned into new products. This research aimed to point out the productive aspects and the acceptability of fish pate prepared from residues of dorado (Brachyplatystoma rousseauxii) supplemented with smoked pirarucu (Arapaima gigas), using the natural potato and cassava thickeners. From the golden carcasses, the muscle mass was extracted, which was later crushed and washed; the pieces of pirarucu loin were smoked and reserved. All ingredients were homogenized in multiprocessor. The following were quantified: a) microbiological contamination of the mass; (b) the yields of golden-washed muscle mass and ground plus smoked pirarucu; c) the acceptability of the different formulations of the smoked pirarucu bream pâté. The formulations were F43M, F43B, F39M and F39B, where the number indicates the amount of fish and the last letter the thickener used. The mass presented low index of microbial contamination. The yields were satisfactory, and it can be pointed out that the transformation of this mass into pâté reduces by $16.98 \%$ the waste disposal in the wild. The highest acceptability of the pâté was in the formulation with the least amount of dormant associated with potato as a thickener. Although changes in the suggested formulations are necessary, it was found that the use of waste from the fishing industry for the production of pâté for human consumption was feasible, potentially reducing $170 \mathrm{~kg}$ of material discarded in nature every 1 ton of waste from industrial processing.
\end{abstract}

Keywords: Carcass; Fish; Folder; Industry; Consumption.

Topic: Inovação Tecnológica

Reviewed anonymously in the process of blind peer.
Received: $18 / 08 / 2018$

Approved: 24/08/2018
Keila Daniellen Pantoja Paiva Caldas (D)

Universidade Federal do Oeste do Pará, Brasil

http://lattes.cnpq.br/8377017303508060

http://orcid.org/0000-0001-8174-3997

keiladaniellen28@gmail.com

Paulo Roberto Brasil Santos (iD)

Universidade Federal do Oeste do Pará, Brasi

http://lattes.cnpq.br/9558469007033186

http://orcid.org/0000-0003-2454-3061

paulobrasil pesca@hotmail.com

Nome Completo (D)

Universidade Federal do Oeste do Pará, Brasil

http://lattes.cnpq.br/9901800939971357

http://orcid.org/0000-0001-8178-393X

herlon.atayde@ufopa.edu.br

a

DOI: 10.6008/CBPC2179-6858.2018.006.0020
Referencing this:

CALDAS, K. D. P. P.; SANTOS, P. R. B.; ATAYDE, H. M.. Patê de peixe usando resíduos da indústria pesqueira amazônica: produção e aceitação. Revista Ibero-Americana de Ciências Ambientais, v.9, n.6, p.188-198, 2018. DOI: http://doi.org/10.6008/CBPC2179$\underline{6858.2018 .006 .0020}$ 


\section{INTRODUÇÃO}

A demanda pelo pescado vem aumentando nos últimos anos, impulsionada, principalmente, pelo crescimento da população e pela tendência mundial, quanto à busca de alimentos saudáveis. Essa busca é consequência da nova postura adotada pelo mercado consumidor, preocupado com a saúde e a preservação ambiental (SALGADO, 2011).

Hoje, há diversas alternativas para aumentar o consumo de pescado, de forma a agregar valor aos produtos, fortalecer a cadeia produtiva e favorecer a produção de alimentos práticos além das usuais formas (pescado fresco, congelado, seco ou enlatado), com alto valor nutritivo (JAMAS, 2012). Apesar disso, aproximadamente $60 \%$ do pescado processado é responsável pela geração de resíduos, enquanto apenas 40\% são designados para o consumo humano (CHALAMAIAH et al., 2012).

Com o aumento da demanda de pescado beneficiado para exportação, há, consequentemente, um aumento nos subprodutos (cabeças, vísceras e espinhas entre outros), potencialmente valiosos caso sejam transformados em novos produtos (FAO, 2014). De acordo com Feltes et al. (2012), a viabilidade do aproveitamento dos resíduos do peixe visando a produção de alimentos para o consumo humano depende, fundamentalmente, da qualidade da matéria-prima, pois a perecibilidade do tecido dos peixes é maior que a de outras espécies animais.

Resíduos de peixes, principalmente oriundos do processo industrial de filetagem, apresentam um baixo valor comercial, sendo normalmente descartados. Entretanto, geralmente apresentam características microbiológicas adequadas e podem agregar valor quando reaproveitados na fabricação de farinhas de pescado. Este e demais produtos são uma opção de renda para as indústrias e para a redução da contaminação industrial do meio ambiente, dando ao pescado uma imagem mais aceitável e tornando-o mais acessível aos consumidores (FOLLMANN et al., 2013).

Em virtude dos altos custos de produção e dos cuidados com a preservação do meio ambiente, as indústrias deveriam utilizar o pescado na sua totalidade, evitando o desperdício e aumentando sua rentabilidade. Por exemplo, deveriam utilizar pequenas aparas e cortes de baixo valor comercial para elaborar produtos de elevado valor nutricional, com características sensoriais desejáveis e de alto valor agregado (PALMEIRA et al., 2014), por exemplo, o patê.

A legislação brasileira define como patê o produto cárneo obtido a partir de carnes, de miúdos das diferentes espécies animais ou de produtos cárneos, transformados em pasta, com adição de ingredientes e submetido a processo térmico específico (BRASIL, 2017); apresenta diversos benefícios, como uma quantidade significativa de proteínas, sais minerais e lipídios, em especial aqueles do tipo ácidos graxos polinsaturados da família ômega-3 e ômega-6 (LOBO, 2014). Para a produção do patê, diversos agentes espessantes podem ser empregados, preferencialmente as féculas de batata ou de mandioca, pois as pastas obtidas desses vegetais geralmente permanecem mais claras (menos opacas) (FIB, 2015) e podem imprimir características gustativas interessantes.

Considerando todo esse cenário mercadológico, essa pesquisa teve por finalidade apontar os aspectos produtivos (formulação e preparo) e comercial (aceitabilidade) do patê de resíduos de dourada 
(Brachyplatystoma rousseauxii) suplementado com o lombo de pirarucu (Arapaima gigas) defumado como alternativa de alimento saudável e de alto valor nutricional, diminuindo o desperdício na natureza e, consequentemente, problemas ambientais.

\section{METODOLOGIA}

\section{Coleta do pescado}

Para esse trabalho, foram considerados como resíduos de pescado as carcaças (formadas pelas espinhas neurais e hemais com resíduo muscular aderido, além de nadadeira caudal) de dourada ( $B$. rousseauxii) proveniente da filetagem efetuada na Indústria de Beneficiamento de Pescado Edifrigo Comercial e Industrial Ltda., no município de Santarém (PA).

Necessariamente, esses resíduos deveriam apresentar coloração esbranquiçada e levemente rosada no músculo, poucas zonas hemorrágicas, sangue de coloração vermelho claro e odor suave, característico de peixe fresco. Carcaças que não apresentaram tais características foram desprezadas como amostra. No total, foram obtidos $32.792,34 \mathrm{~g}$ de amostras. Adicionalmente, foram adquiridos $3.000 \mathrm{~g}$ de lombo de pirarucu fresco, com aspecto sensorial aceitável, em uma das principais feiras municipais - o Mercadão 2000, o qual foi posteriormente utilizado no processo de defumação.

\section{Obtenção da massa muscular e do triturado lavado}

Os resíduos de dourada foram lavados em água clorada, pesados e, em seguida, com auxílio de uma faca, raspados manualmente para a extração do músculo aderido aos ossos. O produto extraído foi denominado massa muscular. Essa massa foi inserida em pequenas porções no moinho manual e o produto moído obtido foi denominado triturado. Esse triturado foi submetido a três sucessivas lavagens com água clorada, previamente resfriada até aproximadamente $10^{\circ} \mathrm{C}$ sob ação do gelo em escamas (triturado:gelo:água na proporção 1:2:2, kg:kg:L), por aproximadamente cinco minutos de duração cada (três minutos sob agitação constante; dois minutos em repouso, para sedimentação). Após cada lavagem, as amostras foram drenadas manualmente em tecido de algodão previamente higienizado, obtendo-se o triturado lavado, mantido sob congelamento até o resultado das análises microbiológicas.

\section{Análise microbiológica do triturado lavado}

Para verificar a viabilidade quanto ao uso do triturado de dourada obtido a partir de resíduos, foram efetuadas a quantificação de coliformes termotolerantes e presença/ausência de Salmonella sp em 25g. A contagem de coliformes termotolerantes foi realizada através do sistema 'Simplate Test Procedures', que recebeu o certificado de aprovação da AOAC 97030 de 05/03/97, para determinação do Número Mais Provável (NMP) por g de amostra, com o auxílio de tabela que acompanha o sistema analítico. A determinação de presença/ausência de Salmonella sp em $25 \mathrm{~g}$ de triturado seguiu a metodologia clássica aprovada pela AOAC (2016), em triplicata. 


\section{Defumação do pirarucu}

Para o processo de defumação à quente foram utilizados $3 \mathrm{~kg}$ de lombo de pirarucu (A. gigas) fresco. Os demais ingredientes utilizados (sal, molho shoyu) foram adquiridos no mercado local, sem priorizar qualquer uma das marcas comerciais disponíveis. O produto defumado foi desenvolvido no Laboratório de Ensino Multidisciplinar de Recursos Aquáticos, Campus Tapajós - UFOPA. Para a defumação, foi utilizado o pó de serragem e lascas de madeira da árvore muiracatiara (também conhecida como aroeira (Astronium lecointei) coletado em uma unidade local beneficiadora de madeira.

A defumação ocorreu a $80^{\circ} \mathrm{C}$ por seis horas. A cada hora ocorreu um rodízio da posição dos cortes no defumador, para assegurar uma defumação uniforme. Após a defumação, o produto filé de pirarucu defumado foi embalado em filme plástico transparente, identificado e mantido congelado, para posterior elaboração dos patês.

\section{Formulação e preparo do patê}

Previamente, foram efetuados testes-piloto com intuito de verificar a influência do quantitativo de lavagens (uma, duas e três) nas características sensoriais do patê. Nesses estudos preliminares, verificou-se que o cheiro mais forte de peixe (mais intenso conforme o menor número de lavagens) interferia negativamente nas características sensoriais desse produto. Diante dessa situação, optou-se pela formulação do patê somente utilizando o triturado submetido às três lavagens, sendo o seu preparo conduzido conforme os trabalhos de Minozzo et al. (2010), Alberto (2014) e Lobo (2014). Para a elaboração das quatro formulações de patê, foram utilizados $972,70 \mathrm{~g}$ de triturado lavado, devidamente descongelados e drenados, em seguida divididos em quatro porções, as quais foram utilizadas para a elaboração de quatro formulações.

Quadro 1: Formulações de patê elaborado a partir da pasta de dourada incrementado com pirarucu defumado.

\begin{tabular}{|l|l|c|c|c|c|}
\hline \multicolumn{2}{|c|}{ INGREDIENTES (quantidades) } & \multicolumn{4}{c|}{ FORMULAČ̃ES } \\
\cline { 3 - 5 } & F43M & F43B & F39M & F39B \\
\hline 1. & Triturado de dourado (g) & 43 & 43 & 39 & 39 \\
\hline 2. & Cebola picada (g) & 0,5 & 0,5 & 0,5 & 0,5 \\
\hline 3. & Alho picado (g) & 0,5 & 0,5 & 0,5 & 0,5 \\
\hline 4. & Coentro (g) & 0,5 & 0,5 & 0,5 & 0,5 \\
\hline 5. & Cebolinha (g) & 0,5 & 0,5 & 0,5 & 0,5 \\
\hline 6. & Cominho(g) & 0,2 & 0,2 & 0,2 & 0,2 \\
\hline 7. & Sal de cozinha (g) & 0,7 & 0,7 & 0,7 & 0,7 \\
\hline 8. & Pimenta do reino (g) & 0,3 & 0,3 & 0,3 & 0,3 \\
\hline 9. & Pimenta cheirosa (g) & 0,5 & 0,5 & 0,5 & 0,5 \\
\hline 10. & Salsinha (g) & 0,5 & 0,5 & 0,5 & 0,5 \\
\hline 11. & Azeite de oliva (ml) & 5 & 5 & 5 & 5 \\
\hline 12. & Água (ml) & 10 & 10 & 10 & 10 \\
\hline 13. & Limão (ml) & 5 & 5 & 5 & 5 \\
\hline 14. & Pirarucu defumado (g) & 4,3 & 4,3 & 3,9 & 3,9 \\
\hline 15. & Macaxeira cozida (g) & 15,0 & 0 & 15,0 & 0 \\
\hline 16. & Batata cozida (g) & 0 & 15,0 & 0 & 15,0 \\
\hline 17. & Gordura hidrogenada (g) & 0,7 & 0,7 & 0,7 & 0,7 \\
\hline 18. & Água (ml) & 5 & 5 & 5 & 5 \\
\hline
\end{tabular}

Em uma panela de alumínio, os ingredientes (de 1 até 14 do quadro 1 ) foram refogados à $90^{\circ} \mathrm{C}$ por 30 minutos, continuamente revolvidos até evaporação da água. Após essa etapa, a massa cozida foi resfriada em temperatura ambiente por 5 minutos e, utilizando-se um multiprocessador em rotação 1 (suave), foi 
misturada aos demais ingredientes (de 15 a 18 do quadro 1 ) conforme cada formulação, por mais 3 minutos, para a homogeneização. Os patês obtidos foram armazenados em embalagem plásticas com tampas, todas identificadas e mantidas sob refrigeração até o início da análise sensorial.

\section{Análise de rendimentos}

Para o rendimento $(R)$, foi utilizada a fórmula $R=(P f \div P i) \times 100$ (SOUZA et al., 2011), onde Pf equivaleu ao peso final alcançado pelo produto (massa muscular, triturado lavado, defumado ou patê) e $\mathrm{Pi}$, o peso da matéria-prima inicial (resíduos, massa muscular, lombo fresco de pirarucu ou triturado lavado) de cada etapa considerada (obtenção da massa muscular e do triturado lavado, defumação do pirarucu ou formulação e preparo do patê). Os resultados foram expressos em porcentagem (\%).

\section{Análise sensorial}

Para a análise de preferência dos patês foi utilizada a escala hedônica com pontuação de 1 a 5 (sendo 1=Péssimo, 2=Regular, 3=Bom, 4=Muito bom e 5=Excelente), segundo Minozzo et al. (2010) e Amorim (2012). Cada formulação foi servida em pedaços diferentes de pão-de-forma devidamente codificados, sendo a associação entre o código e a formulação de conhecimento sigiloso do preparador do teste sensorial. Esse teste foi aplicado a 59 provadores (pessoas não-treinadas, acadêmicos e/ou funcionários do Instituto de Ciências e Tecnologia das Águas, da Universidade Federal do Oeste do Pará), compostos de 32 mulheres (54\%) e 27 homens (46\%).

Entre as formulações, os provadores foram orientados a tomar água mineral em quantidade suficiente para neutralizar as sensações residuais provenientes da formulação anteriormente degustada. Os provadores participantes desse trabalho ainda puderam ser agrupados conforme o sexo e grau de escolaridade - 'médio completo', 'superior incompleto' e 'superior completo' - contabilizando 0, 26 e 6 mulheres e 2, 17 e 8 homens, respectivamente. Ainda, estes provadores puderam ser categorizados conforme três faixas etárias: 17-25, 26-34 e 35-52 anos.

\section{Análises estatísticas}

Foram realizadas análises de variância (ANOVA) e teste de Tukey a posteriori, todos em nível de significância de 5\%, para comparação das médias dos atributos sensoriais por formulação e para verificar as diferenças significativas entre a aceitação global de cada formulação em relação aos fatores gênero, grau de escolaridade e faixa etária. Todas as análises foram realizadas no software PAST 2.17 (HAMMER et al., 2001).

\section{RESULTADOS}

\section{Rendimentos}

Foram obtidos $5.570,01 \mathrm{~g}$ de massa, equivalente a $16,98 \%$ de rendimento em relação ao total de carcaça. Para a produção do triturado lavado, obteve-se rendimento de 1.107,00g, equivalente a 19,87\% em relação à massa utilizada. O lombo defumado de pirarucu apresentou $1.975,46 \mathrm{~g}$, equivalente a $65 \%$ de 
rendimento em relação ao lombo in natura. Os rendimentos de patê foram $202,79 \%$ e $210,77 \%$ nas formulações com $39 \%$ e $43 \%$ de espessante, respectivamente.

\section{Análises microbiológicas}

As amostras de triturado lavado apresentaram como resultado microbiológico a ausência efetiva ( $<10 \mathrm{NMP} / \mathrm{g})$ de coliformes termotolerantes e Staphylococcus coagulase positiva, também ausência de Salmonella $s p$. em $25 \mathrm{~g}$ de amostra. Preferências dos consumidores quanto a aceitação global dos patês: Todas as formulações receberam nota equivalente ao conceito bom; adicionalmente, se verificou ligeira preferência pela formulação com menor quantitativo de peixe e associação de batata utilizada como espessante (tabela 1).

Tabela 1: Dados estatísticos da análise sensorial das formulações de patê de resíduos de dourada suplementado com pirarucu defumado e diferentes agentes espessantes.

\begin{tabular}{|l|c|c|c|c|}
\hline \multirow{2}{*}{ Dados estatísticos } & \multicolumn{4}{|c|}{ Formulações de patê de peixe } \\
\cline { 2 - 5 } & F43M & F43B & F39M & F39B \\
\hline Média \pm desvio-padrão & $2,98 \pm 0,70$ & $3,13 \pm 0,81$ & $3,14 \pm 0,73$ & $3,16 \pm 0,74$ \\
\hline Número amostral & 59 & 59 & 59 & 59 \\
\hline Erro padrão & 0,09 & 0,10 & 0,09 & 0,09 \\
\hline
\end{tabular}

Analisando separadamente os atributos de cada formulação, verifica-se que a cor e odor foram mais satisfatórios para a maioria das formulações (figura 1). Adicionalmente, foi possível verificar a influência do sexo (figura 2), nível de escolaridade (figura 3) e faixa etária (figura 4) na aceitação global do patê de peixe analisado nessa pesquisa. Constatou-se que as formulações de patê de dourada foram mais bem aceitas quando apresentavam menor quantidade de triturado lavado, indicando que as formulações com menos peixe são as mais apreciadas pelos provadores.

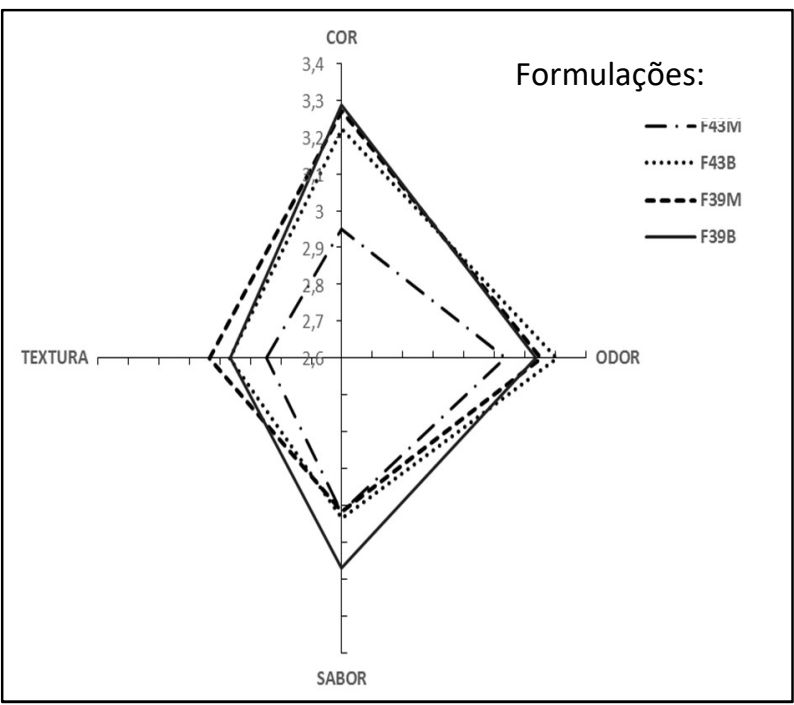

Figura 1: Perfil de atributos (escala sensorial hedônica de cinco pontos) de patês de dourada suplementado com pirarucu defumado e diferentes agentes espessantes. Nas formulações (F), os números e a última consoante indicam, respectivamente, a quantidade de triturado lavado e o espessante $(M=$ macaxeira e $\mathrm{B}=$ batata) utilizados.

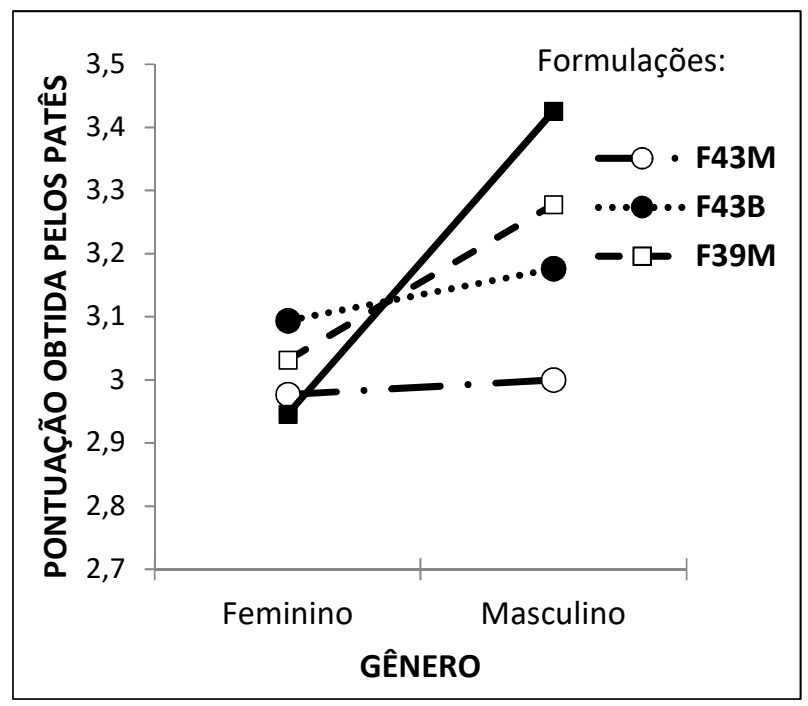

Figura 2: Influência do gênero na aceitabilidade (escala sensorial hedônica de cinco pontos) de patês de dourada suplementado com pirarucu defumado e diferentes agentes espessantes. Nas formulações (F), os números e a última consoante indicam, respectivamente, a quantidade de triturado lavado e o espessante ( $M=$ macaxeira e $B=$ batata) utilizados. 


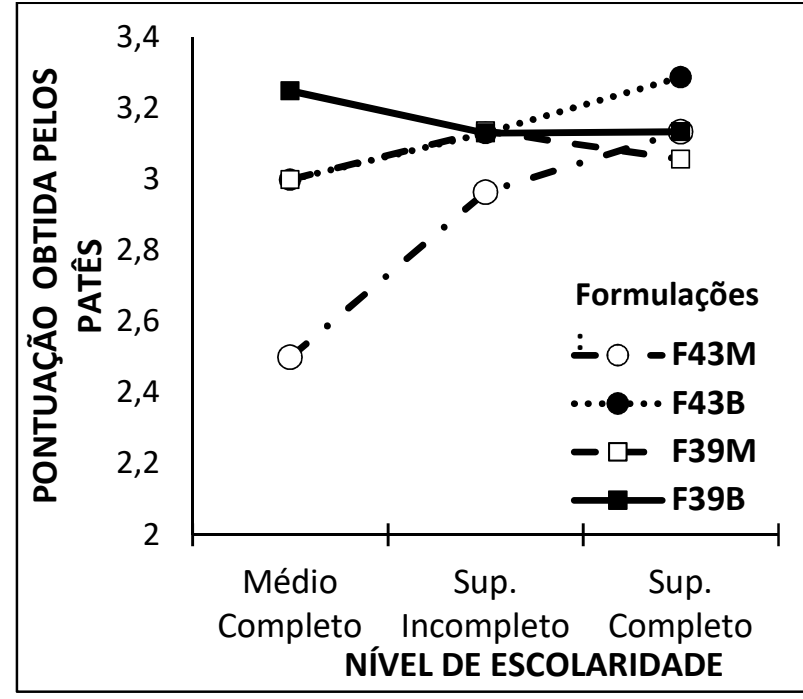

Figura 3: Influência do grau de escolaridade na aceitabilidade (escala sensorial hedônica de cinco pontos) de patês de dourada suplementado com pirarucu defumado e diferentes agentes espessantes. Nas formulações (F), os números e a última consoante indicam, respectivamente, a quantidade de triturado lavado e o espessante ( $M=$ macaxeira e $B=$ batata) utilizados.

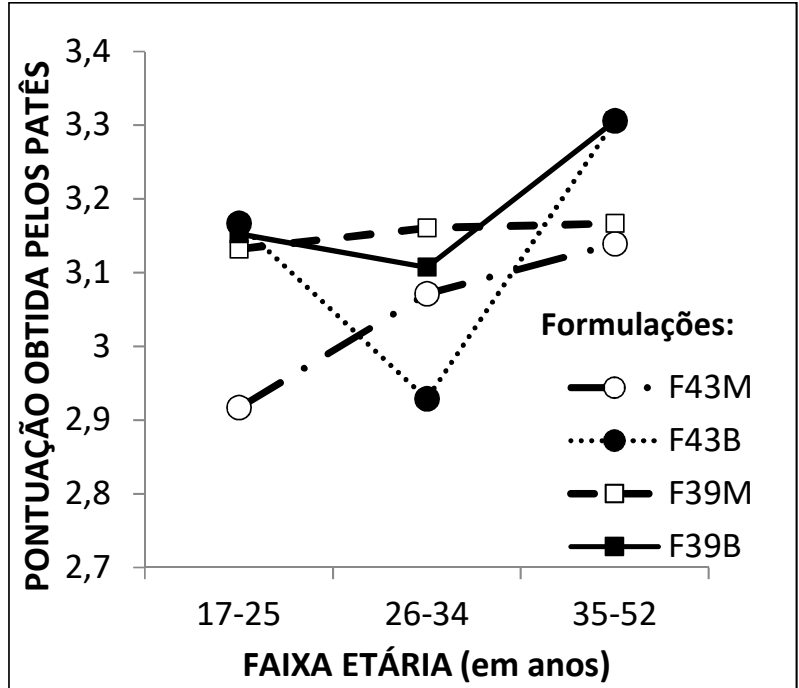

Figura 4: Influência da faixa etária na aceitabilidade (escala sensorial hedônica de cinco pontos) de patês de dourada suplementado com pirarucu defumado e diferentes agentes espessantes. Nas formulações (F), os números e a última consoante indicam,

respectivamente, a quantidade de triturado lavado e o espessante ( $M=$ macaxeira e $B=$ batata) utilizados.

\section{DISCUSSÃO}

Esses rendimentos estão bem abaixo do rendimento médio de $63,48 \%$ obtido por Gomiero et al. (2003) em triturado de matrinxã (Brycon cephallus) a partir do filé desse peixe. O rendimento de $32,7 \%$ obtido por Souza et al. (2000) em filé de tilápia-do-Nilo (Oreochromis niloticus) também é superior ao obtido nessa pesquisa. Estes e demais trabalhos sobre rendimento de massa mencionam o uso de peixes inteiros ou, no máximo, eviscerados, sendo inexistentes na literatura os dados sobre o rendimento de massa obtidos a partir dos resíduos (carcaça). Apesar do rendimento cárneo estar relacionado ao sexo, tamanho ou idade do animal e destreza do filetador (MACEDO-VIEGAS et al., 2000), especialmente para essa pesquisa a diferença de rendimento é influenciada pelo uso de carcaça como matéria-prima que, quando comparada ao peixe inteiro ou filé, apresenta baixo quantitativo de músculo aderido.

Um aspecto importante a ser enfatizado com base nesses dados de rendimento é a possibilidade de redução de $170 \mathrm{~kg}$ de descarte a partir de uma tonelada de resíduos de dourada, pois esse quantitativo (equivalente à massa muscular) é passível de utilização em outras aplicações alimentícias destinadas ao consumo humano. Os $830 \mathrm{~kg}$ restantes são passíveis de utilização na alimentação animal, por exemplo, como ensilado, farinha de peixe ou similares.

Em relação ao triturado lavado, os resultados analisados por Park et al. (2005) mostrou que o aumento do tempo de lavagem não aumentou a remoção das proteínas sarcoplasmáticas, sendo que três ciclos de lavagem de amostras contendo 2:1 (água: peixe) foram recomendados para elaboração do surimi. O rendimento após o processo de lavagem pode ser influenciado pela eficiência da retirada da água, número de lavagens e tipo de equipamento utilizado (KIRSCHNIK et al., 2013). Jamas (2012) obteve rendimento de $82,88 \%$ em CMS para tilápia após dois ciclos de lavagem. Os rendimentos de triturado foram menores nesse 
trabalho, provavelmente influenciados pelos números de lavagens (três) e a matéria prima utilizada (carcaça). Visivelmente, já se constata que essa carcaça apresenta menor quantitativo de massa muscular quando comparado a um peixe inteiro ou eviscerado.

Para o pirarucu defumado, as perdas durante a defumação nesse estudo (35\%) foram maiores que a faixa de 10 até $25 \%$ apontada por Santos et al. (2007), que também menciona que estas perdas dependem do tipo de material in natura, característica do produto final e parâmetros usados no processo, tais como tempo e temperatura. A perda de rendimento dessa pesquisa pode ser atribuída à quantidade considerável de pele e gorduras retiradas da amostra antes da defumação.

Os rendimentos em patê foram satisfatórios e permitem apontar que seriam necessários aproximadamente $128 \mathrm{~g}$ de carcaça para produzir $87,20 \mathrm{~g}$ ou $82,20 \mathrm{~g}$ dos patês, respectivamente. Em escala maior, significa que uma tonelada de resíduos de dourada poderiam originar, em média, $660 \mathrm{~kg}$ de um produto com excelente rendimento e valor agregado, minimizando a quantidade descartada na natureza e, consequentemente, os possíveis e sérios danos ambientais decorrentes dessa prática.

Os índices microbiológicos obtidos estão em conformidade com os padrões estabelecidos pela legislação brasileira (BRASIL, 2001). Resultados similares foram encontrados por Ribeiro et al. (2009) em amostras oriundas de coletas realizadas no Rio de Janeiro em 11 indústrias de pescado pelo Ministério da Agricultura, Pecuária e Abastecimento, onde verificou a ausência destes mesmos microrganismos para pescados processados que possuíam origem de frigoríficos. Portanto, as carcaças provenientes do frigorífico são adequadas como matéria-prima para a produção de alimentos destinados ao consumo pelo homem, como exemplo o patê de dourada.

Quanto ao resultado da análise sensorial, a formulação que obteve maior pontuação global $(3,16$; equivalente ao conceito bom) apresentava o menor quantitativo de triturado dos resíduos de dourada e espessante natural de batata (cozida). Médias semelhantes foram observadas por Sebben et al. (2000), que avaliaram os mesmos atributos para hambúrgueres de carpa comum (Cyprinus carpio) elaborados com surimi lavado três vezes e obtiveram médias de 3,13 para aparência; 3,75 para odor; 2,81 para gosto e 3,13 para textura, também utilizando uma escala hedônica que variava de 0 a 5 pontos.

Ganham destaque na presente pesquisa a cor e odor (figura 1) das formulações contendo batata 3,28 para F39B e 3,30 para F43B, mesmo que não tenham utilizado qualquer tipo de corante ou aromatizante artificial no seu preparo. No entanto, o sabor (figura 1) de F39B provavelmente foi o atributo numericamente diferenciador na maior aceitação global dessa formulação. Para outro produto - muxama de pirarucu, um produto defumado - foi observado por Carvalho (2015), que os atributos aroma e sabor foram os critérios mais bem avaliados (63\% e $67 \%$ respectivamente) pelos provadores.

A pesquisa de Beirão et al. (1999) apontou maior aceitação para o patê de carne de cação-martelo, pois sua formulação continha páprica doce, agindo de certa forma como corante, fato que consequentemente contribuiu de forma positiva para sua aceitação. Aqueretta et al. (2002) desenvolveu patês com carne de cavala (Scomber japonicus) e de fígado de atum (Thunnus albacares) e obtiveram notas inferiores para odor e gosto de peixe, os quais foram considerados muito fortes, especialmente nas 
formulações onde continham maior quantidade de fígado de atum. Nesse estudo, as maiores pontuações de aceitação foram para o odor nas formulações com menor quantidade de triturado de dourada; a cor apresentou segunda maior pontuação. Pela análise de aceitação por atributos, não houve uma diferença significativa entre as quatro formulações $(F=0,6861 ; p$ valor=0,5613).

A influência do gênero na aceitabilidade das formulações (Figura 2) foi similar aos dados obtidos por Carvalho (2015) analisando outros produtos a partir de pirarucu defumado, onde os homens apontaram as maiores notas de preferência. Nessa pesquisa, todas as formulações continham defumado e os homens expressaram maior preferência $(3,42)$ quando comparado às mulheres $(3,09)$, apesar de ambas as notas serem equivalentes ao conceito bom.

Quando avaliada a aceitação global por formulação de patê (tabela 1), as formulações F39B e F43M receberam as menores médias pelo sexo feminino para todas as características. Os homens apresentaram maior preferência pelo produto patê, especialmente F39B. Houve diferença significativa entre os gêneros $(F=4,5734 ; p=0,03354)$, indicando que os indivíduos masculinos deverão ser alvos preferenciais em divulgações comerciais do patê com defumado, caso seja lançado no mercado.

Conforme a figura 3 , os provadores com ensino médio completo demonstraram tendência à rejeição pelo patê; no entanto, provadores com ensino superior completo mostraram aceitação pelo mesmo produto. A percepção dos provadores para as formulações com maiores quantidade de peixes são ligeiramente diferenciadas, especialmente preteridas nas faixas de idade (figura 4) entre 17-25 para F43M e 26-34 para F43B. Apesar disso, nas análises estatísticas de aceitação global do patê em relação ao grau de escolaridade (figura 3) e as faixas etárias (figura 4) não se constatou diferença significativa ( $F=0,3144 \mathrm{p}=0,8681$ e $F=0,5710$; $p=0,5658$, respectivamente), ou seja, o patê de dourada será consumido no mercado, independente da escolaridade e faixa etária.

Estudos para aperfeiçoar as formulações deste patê de dourada ainda são válidos, pois viabilizam uma formulação melhorada, na intenção de alcançar uma nota mais alta nas análises sensoriais e tornandoo mais aceito pelo consumidor final. Considerando as formulações testadas nesse trabalho, foi mais aceitável o patê com uma menor quantidade de triturado lavado em associação com o uso da batata. Ainda, é necessário verificar se a mistura dos espessantes batata e macaxeira na formulação contribuirão na aceitação, sempre com menor quantidade de peixe, pois esses espessantes imprimiram características diferentes para cada atributo.

\section{CONCLUSÕES}

As análises microbiológica e sensorial nessa pesquisa apontaram que a carcaça da dourada oriunda da indústria é adequada para o aproveitamento como alimento humano. O rendimento em massa muscular de peixe a partir dessas carcaças também foi satisfatório, similar ao observado no defumado. Quando transformada em patê de peixe, sua aceitabilidade foi afetada pela quantidade de triturado utilizado, sendo favorável às formulações com menor quantidade. Nessa pesquisa, foi possível avaliar que são necessárias mudanças nas formulações sugeridas, para que o patê de peixe seja mais atrativo ao consumidor. Mais 
importante, verificou-se a viabilidade para a produção e comercialização desse patê a partir dos resíduos de carcaça, pois essa iniciativa tem relevante impacto na conservação ambiental.

\section{REFERÊNCIAS}

ALBERTO, C. N.. Valorização de produtos de pesca: produção de filetes e paté de carapau fumado. Dissertação (Mestrado em Empreendedorismo e Inovação na Indústria Alimentar) - Escola Superior de Tecnologia e Gestão do Instituto Politécnico de Viana do Castelo, Viana do Castelo, 2014.

AMORIM, E. L.. Análise sensorial de fishburguer de carne triturada de aruanã (Osteoglossum sp.) com diferentes agentes espessantes. Monografia (Graduação em Tecnologia de Alimentos) - Universidade do Estado do Amazonas, Tapauá, 2012.

AOAC. Association of Official Analytical Chemists. Official methods of analysis. 17 ed. Gaithersburg: AOAC, 2016.

AQUERRETA, Y.; ASTIASARÁM, I.; MOHINO, A.; BELLO, J.. Composition of pâtés elaborated with mackerel flesh (Scomber scombrus) and tuna liver (Thunnus thynnus): comparison with commercial fish pâtés. Food Chemistry, v.77, p.147-153, 2002. DOI: https://doi.org/10.1016/S03088146(01)00310-7

BEIRÃO, L. H.; DALBÓ, A.. Utilización de surimi de carne de tiburón-martillo (Sphyrna zygaena) en la producción de patés. In: MEMORIAS SEGUNDO SIMPOSIUM IBEROAMERICANO DE ANÁLISIS SENSORIAL. Anais. Cidade do México: 1999.

BRASIL. Decreto n.9013, de 29 de março de 2017. Regulamenta a Lei no1.283, de 18 de dezembro de 1950, e a Lei $n$ o 7.889, de 23 de novembro de 1989, que dispõem sobre a inspeção industrial e sanitária de produtos de origem animal. Brasília: DOU, 2017.

BRASIL. Resolução RDC $\mathbf{n} . \mathbf{1 2}$, de 02 de janeiro de 2001 Aprova o Regulamento Técnico sobre os Padrões Microbiológicos para Alimentos. Brasília: DOU, 2001.

CARVALHO, D. A. P.. Aceitabilidade de diferentes cortes de Arapaima gigas (CUVIER, 1829) curados e defumados. Monografia (Graduação em Engenharia de Aquicultura) Universidade Federal de Santa Catarina, Florianópolis, 2015.

CHALAMAIAH, M.. Fish protein hydrolysates: proximate composition, amino acid composition, antioxidant activities and applications: a review. Food Chemistry, v.135, p.30203038, 2012. DOI:

https://doi.org/10.1016/i.foodchem.2012.06.100

FAO. Food Agriculture Organization of the United Nations. 0 comércio global de pescado atinge níveis recordes. Roma: FAO, 2014.

FELTES, M. M. C.; CORREIA; J. F. G.; BEIRÃO, L. H.; BLOCK, J. M.; NINOW J. L.; SPILLER, V. R.. Alternativas para a agregação de valor aos resíduos da industrialização de peixe. Revista Brasileira de Engenharia Agrícola e Ambiental, Campina Grande, v.14, n.6, p.669-677, 2012. DOI: http://doi.org/10.1590/S1415-43662010000600014
FIB. FOOD INGREDIENTS BRASIL. Amidos. Revista Food Ingredients Brasil, São Paulo, n.35, p.33, 2015.

FOLLMANN, A. M. C.; CENTENARO, A. I.. Elaboração de bolo de laranja adicionado com diferentes concentrações de farinha de carcaça de tilápia-do-Nilo (Oreochromis niloticus). Monografia (Graduação em Tecnologia em Alimentos) - Universidade Tecnológica Federal do Paraná, Curitiba, 2013.

GOMIERO, J. S.; GUEDES, P. P. A.; RIBEIRO, M. W. F; LOGATO, P. V. R.. Rendimento de carcaça de peixe matrinxã (Brycon cephalus) nos diferentes cortes de cabeça. Ciência e agrotecnologia, Lavras, v.27, n.1, p.211-216, 2003. DOI: http://doi.org/10.1590/S1413-70542003000100027

HAMMER, $\varnothing$.; HARPER, D. A. T.; RYAN, P. D.. PAST:

Palaeontological statistics software package for education and data analysis. Palaeontologia Electronica, Califórnia, v.4, n.1, 2001.

JAMAS, E.. Valor agregado aos resíduos do processamento de tilápia: aspectos tecnológicos, químicos e microestruturas. Dissertação (Mestrado em Aquicultura) Universidade Estadual Paulista Centro de Aquicultura da Unesp, Jaboticabal, 2012.

KIRSCHNIK, P. G.; TRINDADE, M. A.; GOMIDE, C. A.; MORO, M. E. G.; VIEGAS, E. M. M.. Estabilidade em armazenamento da carne de tilápia-do-Nilo mecanicamente separada, lavada, adicionada de conservantes e congelada. Pesquisa Agropecuária Brasileira, Brasília, v.48, n.8, p.935-942, 2013. DOI: http://doi.org/10.1590/S0100-204X2013000800018

LOBO, C. M. O.. Elaboração de patê e filé em conserva utilizando cachapinta (Pseudoplatystoma sp.). Tese (Doutorado em Higiene Veterinária e Processamento Tecnológico de Produtos de Origem Animal) - Universidade Federal Fluminense, Niterói, 2014.

MACEDO-VIEGAS, E. M.; SCORVO, C. M. D. F.; VIDOTTI, R. M.; SECCO, E. M.. Efeito das classes de peso sobre a composição corporal e rendimento de processamento da matrinxã cultivada (Brycon cephalus). Acta Scientiarium, Maringá, v.22, n.3, p.725-728, 2000. DOI: Http://doi.org/10.4025/actascianimsci.v22i0.3138

MINOZZO, M. G.; WASZCZYNSKYJ, N.. Caracterização sensorial de patê cremoso elaborado a partir de filés de tilápia-do-Nilo. Revista Brasileira de Engenharia de Pesca, São Luís, v.5, n.2, p.26-36, 2010.

PALMEIRA, K. R.; MÁRSICO, E. T.; DORO, L.; LEMOS, M.; TEIXEIRA, C. E.; PASCHOALIN, V. M. F.; MONTEIRO, M. L. G.; CONTE JÚNIOR, C. A.. Quality of semi-prepared products from rainbow trout waste (Onchorynchus mykiss) by using different technological strategics. Food and Nutrition Sciences, n.5, p.571-580, 2014. DOI: http://doi.org/10.4236/fns.2014.56067 
PARK, J. W.; LIN, T. M.. Surimi: manufacturing and evaluation. In: PARK, J. E.. Surimi and surimi seafood. 2 ed. Boca Raton: CRC Press, 2005. p.33-105.

RIBEIRO, A. L. M. S.; OLIVEIRA, G. M.; FERREIRA, V. M.; PEREIRA, M. M. D.; SILVA, P. P. O.. Avaliação microbiológica da qualidade do pescado processado importado no estado do Rio de Janeiro. Revista Brasileira de Ciência Veterinária, Niterói, v.16, n.3, p.109-112, 2009. DOI:

https://doi.org/10.22409/rbcv.v16i3.323

SALGADO, R. L.. Avaliação parasitológica do pescado fresco comercializado no sudeste do Pará. Revista PUBVET, Maringá, v.5, p.992-998, 2011.

SANTOS, L. D.; ZARA, R. F.; VISENTAINER, J. V.; MATSUSHITA, M.; SOUZA, N. E.; FRANCO, M. L. R. S.. Avaliação sensorial e rendimento de filés defumados de tilápia (Oreochromis niloticus LINNAEUS, 1757) na presença de alecrim (Rosmarinus officinalis). Ciência e Agrotecnologia, Lavras, v.31, n.2, p.406-412, 2007.
SEBBEN, C. L.; BEIRÃO, L. H.; MEINERT, E. M.; TEIXEIRA, E.; DAMIAN, C.. Rendimento e avaliação sensorial de hambúrgueres de carpa (Cyprinus carpio) com diferentes condições de processamento e armazenamento sob congelamento. Boletim do Centro de Pesquisa de Processamento de Alimentos, Curitiba, v.16, n.1, p.2-12, 2000. DOI: http://doi.org/10.5380/cep.v18i1.1120

SOUZA, F. L.; INHAMUNS, A. J.. Análise de rendimento cárneo das principais espécies de peixes comercializadas no Estado do Amazonas, Brasil. Acta Amazônica, Manaus, v.41, n.2, p.289- 296, 2011. DOI: http://doi.org/10.1590/S0044$\underline{59672011000200015}$

SOUZA, M. L. R.; MARENGONI, N. G.; PINTO, A. A.; CAÇADOR, W. C.. Rendimento do processamento da tilápia-do-Nilo (Oreochromis niloticus): tipos de cortes da cabeça em duas categorias de peso. Acta Scientiarum, Maringá, v.22, n.3, p.701-706, 2000. DOI:

http://doi.org/10.4025/actascianimsci.v22i0.2926

A CBPC - Companhia Brasileira de Produção Científica (CNPJ: 11.221.422/0001-03) detém os direitos materiais desta publicação. Os direitos referem-se à publicação do trabalho em qualquer parte do mundo, incluindo os direitos às renovações, expansões e disseminações da contribuição, bem como outros direitos subsidiários. Todos os trabalhos publicados eletronicamente poderão posteriormente ser publicados em coletâneas impressas sob coordenação da Sustenere Publishing, da Companhia Brasileira de Produção Científica e seus parceiros autorizados. Os (as) autores (as) preservam os direitos autorais, mas não têm permissão para a publicação da contribuição em outro meio, impresso ou digital, em português ou em tradução. 